\title{
Robust control technique in power converter with linear induction motor
}

\author{
Nicolás Toro García1, Yeison Alberto Garcés-Gomez², Vladimir Henao-Cespedes² \\ ${ }^{1}$ Department of Electric and Electronics Engineering, Faculty of Engineering and Architecture, Universidad Nacional de Colombia, \\ Manizales, Colombia \\ ${ }^{2}$ Natural Sciences and Mathematics Academic Unit, Faculty of Engineering and Architecture, Universidad Católica de Manizales,
} Manizales, Colombia

\begin{tabular}{l} 
Article Info \\
\hline Article history: \\
Received Jul 6, 2021 \\
Revised Jan 18, 2022 \\
Accepted Jan 25, 2022 \\
\hline Keywords: \\
Control technique \\
Fixed point inducting \\
Linear induction motor \\
Modeling \\
Zero average dynamic
\end{tabular}

\begin{abstract}
Induction motors are widely used in industrial applications as actuators, thanks to their simplicity of construction, which is subsequently reflected in low-cost maintenance. This paper shows the behavior of a three-phase power converter with a linear induction motor (LIM) as load, using a quasi-sliding control technique for output voltage regulation and a new control technique to control chaos. Digital pulse width modulation (DPWM) techniques are widely used to control electronic power converters. The controller proposed in this paper was designed using zero average dynamic (ZAD) and fixed point inducting control (FPIC) techniques. The ZAD-FPIC control strategy was designed and applied to a three-phase converter with linear induction motor load. Since it is not possible to measure the secondary currents, a secondary current observer was included in the system. Finally, bifurcation diagrams are shown as a technique for tuning controller parameters in $\mathrm{ZAD}$ FPIC controllers. For the illustration of numerical results a simulation of the linear induction motor drive controlled was made by MATLAB/Simulink. The designs were tested in a rapid control prototyping (RCP) system based on digital signal processing (DSP) for dSPACE platform, using the 1103 controller card and control desk interface.
\end{abstract}

This is an open access article under the CC BY-SA license.

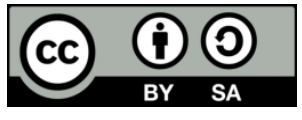

\section{Corresponding Author:}

Yeison Alberto Garcés Gómez

Academic Training Unit in Natural Sciences and Mathematics, Universidad Católica de Manizales

Cra 23 No 60-63, Manizales, Caldas, Colombia

Email: ygarces@ucm.edu.co

\section{INTRODUCTION}

Essentially there are two types of asynchronous motors: the rotary induction motor (RIM) and linear induction motor (LIM). These are widely used in industrial applications as actuators, thanks to their simplicity of construction, which is subsequently reflected in low-cost maintenance [1], [2]. When the topological characteristics of an asynchronous motor, as in the case of developing the LIM from a rotating electrical machine, its operating conditions and design criteria differ, as has been presented in previous publications [3]-[7].

This paper shows the behavior of a three-phase power converter with a LIM motor as load, using a quasi-sliding control technique for output voltage regulation and a new control technique to control chaos. The controller was designed using the following techniques: zero average dynamic (ZAD) and fixed point inducting control (FPIC) [8]-[17]. The designs were tested in a rapid control prototyping (RCP) system based on digital signal processing (DSP) for dSPACE platform. 
Power converters have special interest since it is estimated that $90 \%$ of the electrical energy is processed by these devices before end use [18] and additionally this interest has been increased thanks to the use of removable energy sources [19], [20], using power electronics for the efficient transformation and rational use of electricity from generation sources to industrial and commercial use. Power converters must provide a certain output voltage level, either in regulating or tracking tasks, and be able to accept load changes and variations in the primary supply voltage level. Mohan et al. [21], [22] present a complete and detailed analysis on the operation and configuration of different power converters. By using switching devices that generate a desired output with low power consumption, it is possible to obtain one of the most desirable qualities of power converters and that is efficiency in performance.

On the other hand, the digital pulse-width modulation technique (DPWM) is widely used to control electronic power converters [23], [24], thanks to advantages such as: low power consumption, immunity to variations of analog components, potentially faster design process, lower sensitivity to parameter variations, programmability, reduction or elimination of external passive components, calibration or protection algorithms, ability to interface with digital systems, possibility to implement nonlinear control techniques, and advanced control algorithms, such as parameter estimation, are much easier to implement, as mentioned in [25]-[27].

\section{RESEARCH METHOD}

\subsection{Proposed system}

The proposed controller designed in this paper combines the strategies of zero averaging dynamics (ZAD) and fixed point induction controller (FPIC), presented in [8]-[15]. The design corresponds to the load of a linear induction motor with three-phase low power inverter $(1500 \mathrm{~W})$ which uses a dSPACE platform. The system is divided into hardware and software. In software, the control and signal acquisition techniques were implemented. The hardware is composed of a three-phase converter with a linear induction motor LIM motor as load with a rated power of $1500 \mathrm{~W}$, rated voltage of $600 \mathrm{VDC}$ and rated current of 20 ADC. To obtain the measurements of $v_{c}$ a series resistor was used and for the measurement of $i_{L}$ the current sensor HX10P/SP2 was used. The converter switches were driven by PWM outputs of the controller card, these signals are coupled via fast optocouplers (6N137). The controllers were implemented in simulink and downloaded to a DPS.

\subsection{Mathematical model}

The system implemented for the switched-mode power converter and the linear induction motor LIM coupled system that takes into account the end effects [4], is shown in the Figure 1. To perform a time domain analysis of such a system, it is usually assumed that magnetic saturation, hysteresis and eddy current effects are negligible, yielding in (1) that is the state space model, detailed in (2).

$$
\dot{x}=\mathrm{A}(x) \mathrm{x}+\mathrm{BU}+\mathrm{D}
$$

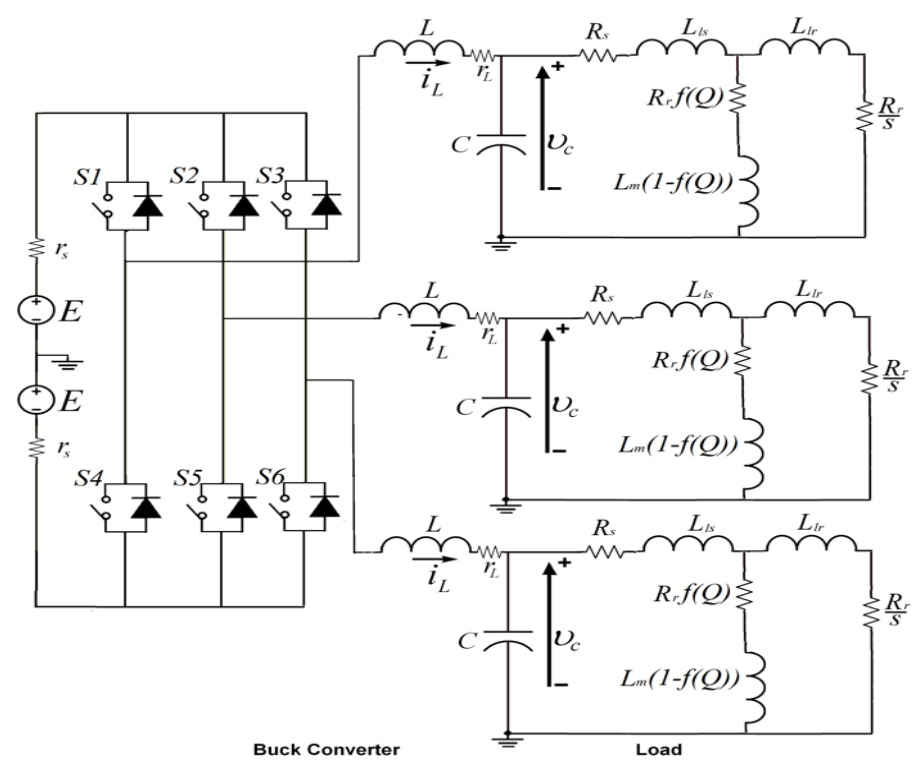

Figure 1. Electric circuit for the converter-motor system 


$$
\left[\begin{array}{c}
i_{L_{a}} \\
\dot{v}_{c_{a}} \\
i_{s_{a}} \\
i_{r_{a}} \\
i_{L_{b}} \\
\dot{v}_{c_{b}} \\
i_{s_{b}} \\
i_{r_{b}} \\
i_{L_{c}} \\
\dot{v}_{c_{c}} \\
i_{s_{c}} \\
i_{r_{c}} \\
\dot{v}_{m}
\end{array}\right]=\left[\begin{array}{ccccccccccccc}
a_{11_{a}} & a_{12_{a}} & 0 & 0 & 0 & 0 & 0 & 0 & 0 & 0 & 0 & 0 & 0 \\
a_{21_{a}} & 0 & a_{23_{a}} & 0 & 0 & 0 & 0 & 0 & 0 & 0 & 0 & 0 & 0 \\
0 & a_{32_{a}} & a_{33_{a}} & a_{34_{a}} & 0 & 0 & 0 & 0 & 0 & 0 & 0 & 0 & 0 \\
0 & a_{42_{a}} & a_{43_{a}} & a_{44_{a}} & 0 & 0 & 0 & 0 & 0 & 0 & 0 & 0 & 0 \\
0 & 0 & 0 & 0 & a_{11_{b}} & a_{12_{b}} & 0 & 0 & 0 & 0 & 0 & 0 & 0 \\
0 & 0 & 0 & 0 & a_{21_{b}} & 0 & a_{23_{b}} & 0 & 0 & 0 & 0 & 0 & 0 \\
0 & 0 & 0 & 0 & 0 & a_{32_{b}} & a_{33_{b}} & a_{34_{b}} & 0 & 0 & 0 & 0 & 0 \\
0 & 0 & 0 & 0 & 0 & a_{42_{b}} & a_{43_{b}} & a_{44_{b}} & 0 & 0 & 0 & 0 & 0 \\
0 & 0 & 0 & 0 & 0 & 0 & 0 & 0 & a_{11_{c}} & a_{12_{c}} & 0 & 0 & 0 \\
0 & 0 & 0 & 0 & 0 & 0 & 0 & 0 & a_{21_{c}} & 0 & a_{23_{c}} & 0 & 0 \\
0 & 0 & 0 & 0 & 0 & 0 & 0 & 0 & 0 & a_{32_{c}} & a_{33_{c}} & a_{34_{c}} & 0 \\
0 & 0 & 0 & 0 & 0 & 0 & 0 & 0 & 0 & a_{42_{c}} & a_{43_{c}} & a_{44_{c}} & 0 \\
0 & 0 & 0 & a_{51} & 0 & 0 & 0 & a_{52} & 0 & 0 & 0 & a_{53} & -\frac{B}{M}
\end{array}\right]\left[\begin{array}{c}
i_{L_{a}} \\
v_{c_{a}} \\
i_{s_{a}} \\
i_{r_{a}} \\
i_{L_{b}} \\
v_{c_{b}} \\
i_{s_{b}} \\
i_{r_{b}} \\
i_{L_{c}} \\
v_{c_{c}} \\
i_{s_{c}} \\
i_{r_{c}} \\
v_{m}
\end{array}\right]
$$

$$
+\left[\begin{array}{ccc}
\frac{E}{L_{a}} & 0 & 0 \\
0 & 0 & 0 \\
0 & 0 & 0 \\
0 & 0 & 0 \\
0 & \frac{E}{L_{b}} & 0 \\
0 & 0 & 0 \\
0 & 0 & 0 \\
0 & 0 & 0 \\
0 & 0 & \frac{E}{L_{c}} \\
0 & 0 & 0 \\
0 & 0 & 0 \\
0 & 0 & 0
\end{array}\right]\left[\begin{array}{c}
0 \\
0 \\
0 \\
S_{2}-S_{5} \\
S_{3}-S_{6}
\end{array}\right]+\left[\begin{array}{c}
0 \\
0 \\
0 \\
0 \\
0 \\
0 \\
0 \\
0 \\
-\frac{F_{L}}{M}
\end{array}\right]
$$

The system is made up of 3 subsystems where each phase can be treated independently. The model per phase, considering $F_{L}=0$ (in 1), can be seen in the (3),

$$
\left[\begin{array}{c}
i_{L} \\
\dot{v}_{c} \\
i_{s} \\
i_{r}
\end{array}\right]=\left[\begin{array}{cccc}
a_{11} & a_{12} & 0 & 0 \\
a_{21} & 0 & a_{23} & 0 \\
0 & a_{32} & a_{33} & a_{34} \\
0 & a_{42} & a_{43} & a_{44}
\end{array}\right]\left[\begin{array}{c}
i_{L} \\
v_{c} \\
i_{s} \\
i_{r}
\end{array}\right]+\left[\begin{array}{c}
\frac{E}{L} \\
0 \\
0 \\
0
\end{array}\right] U_{c}
$$

with $U_{c}=-1,1$ according to switch control.

Where:

$$
\begin{aligned}
& a_{11}=-\frac{r_{s}+r_{L}}{L} \\
& a_{12}=-\frac{1}{L} \\
& a_{21}=\frac{1}{C} \\
& a_{23}=-\frac{1}{C} \quad \\
& a_{32}=\frac{L_{m}(1-f(Q))+L_{l r}}{L_{l s} L_{m}(1-f(Q))+L_{l r} L_{m}(1-f(Q))+L_{l r} L_{l s}} \\
& a_{33}=-\frac{R_{s}\left(L_{m}(1-f(Q))+L_{l r}\right)+R_{r} f(Q) L_{l r}}{L_{l s} L_{m}(1-f(Q))+L_{l r} L_{m}(1-f(Q))+L_{l r} L_{l s}} \\
& a_{34}=-\frac{R_{r} L_{m}(1-f(Q))+s L_{l r} R_{r} f(Q)}{s\left(L_{l s} L_{m}(1-f(Q))+L_{l r} L_{m}(1-f(Q))+L_{l r} L_{l s}\right)} \\
& a_{42}=\frac{L_{m}(1-f(Q))}{L_{l s} L_{m}(1-f(Q))+L_{l r} L_{m}(1-f(Q))+L_{l r} L_{l s}} \\
& a_{43}=-\frac{R_{s} L_{m}(1-f(Q))+R_{r} f(Q) L_{l s}}{L_{l s} L_{m}(1-f(Q))+L_{l r} L_{m}(1-f(Q))+L_{l r} L_{l s}}
\end{aligned}
$$




$$
\begin{aligned}
& a_{44}=-\frac{R_{r}\left(L_{m}(1-f(Q))+L_{l s}+s f(Q) L_{l s}\right)}{s\left(L_{l s} L_{m}(1-f(Q))+L_{l r} L_{m}(1-f(Q))+L_{l r} L_{l s}\right)} \\
& \mathrm{s}=\left(v_{s}-v_{m}\right) / v_{s},
\end{aligned}
$$

$\mathrm{s}$ is the motor slip, $v_{m}$ is the mover speed and $v_{s}$ is the synchronous speed. The mechanical equation is given by (4).

$$
\dot{v_{m}}=\frac{i_{r a}^{2} R_{r_{a}}}{M s v_{s}}+\frac{i_{r b}^{2} R_{r_{b}}}{M s v_{s}}+\frac{i_{r_{c}}^{2} R_{r_{c}}}{M s w_{s}}-\frac{B}{M} v_{m}-\frac{F_{L}}{M}
$$

Then:

$$
\begin{aligned}
& a_{51}=\frac{i_{r_{a}} R_{r_{a}}}{M s v_{s}} \\
& a_{52}=\frac{i_{r_{b}} R_{r_{b}}}{M s v_{s}} \\
& a_{53}=\frac{i_{r_{c}} R_{r_{c}}}{M s w_{s}}
\end{aligned}
$$

\subsection{ZAD-FPIC control strategy}

The ZAD-FPIC control strategy was applied by equivalent phase circuit for the linear induction motor LIM. In the case of a three-phase system, the control must be applied independently in each phase, taking into account that the reference voltage will be shifted according to the phase of the corresponding circuit. Since the mechanical dynamics is very slow compared to the electrical dynamics, the motor speed is considered constant in each sample period.

In order to apply the linear induction motor and fixed point inducting control ZAD-FPIC control strategy, it was necessary to obtain the secondary current in the equivalent circuit of each phase, which is the current through $L_{l r}$ in Figure 1. The original secondary current equation can be used directly as the observer equation. The implementation of such a current observer is the on-line simulation of a controlled linear induction motor. This observer is stable with the convergence rate depending on the secondary time constant, in this case the dynamic observer equation is given by (5).

$$
\begin{aligned}
\frac{d \hat{\iota}_{r}}{d t}= & \frac{L_{m}(1-f(Q))}{L_{l s} L_{m}(1-f(Q))+L_{l r} L_{m}(1-f(Q))+L_{l r} L_{l s}} v_{c} \\
& -\frac{R_{s} L_{m}(1-f(Q))+R_{r} f(Q) L_{l s}}{L_{l s} L_{m}(1-f(Q))+L_{l r} L_{m}(1-f(Q))+L_{l r} L_{l s}} i_{s} \\
& -\frac{R_{r}\left(L_{m}(1-f(Q))+L_{l s}+s f(Q) L_{l s}\right)}{s\left(L_{l s} L_{m}(1-f(Q))+L_{l r} L_{m}(1-f(Q))+L_{l r} L_{l s}\right)} \hat{l}_{r}
\end{aligned}
$$

Where $s=\left(v_{s}-v_{m}\right) / v_{s}$ and $\widehat{v_{r}}$ is the estimate of the per phase secondary current and the error is calculated as $\widetilde{t_{r}}=\widehat{t_{r}}-i_{r}$, obtaining the following error dynamic:

$$
\frac{d \widetilde{l_{r}}}{d t}=-\frac{R_{r}\left(L_{m}(1-f(Q))+L_{l s}+s f(Q) L_{l s}\right)}{s\left(L_{l s} L_{m}(1-f(Q))+L_{l r} L_{m}(1-f(Q))+L_{l r} L_{l s}\right)} \widetilde{l_{r}}
$$

A Lyapunov function is selected as:

$$
V=\frac{1}{2} \widetilde{l_{r}^{2}}>0
$$

And calculate the time derivative of $\mathrm{V}$ along the solution of (6) to yield,

$$
\dot{V}=-\frac{R_{r}\left(L_{m}(1-f(Q))+L_{l s}+s f(Q) L_{l s}\right)}{s\left(L_{l s} L_{m}(1-f(Q))+L_{l r} L_{m}(1-f(Q))+L_{l r} L_{l s}\right)} \widetilde{l_{r}^{2}}<0
$$

This means that if we simply integrate in (5), the mismatch between the real and estimated secondary current tends to zero asymptotically. The rate of convergence may be improved if properly designed observer gain is introduced. 


\section{RESULTS AND DISCUSSIONS}

Figure 2 shows the simulation results of the secondary currents observer (5). To show the convergence process, select as initial conditions the observed currents $i_{\widehat{r_{a}}}=\widehat{r_{r_{b}}}=\widehat{r_{r_{c}}}=3 \mathrm{~A}$, and the real secondary currents $i_{r_{a}}=i_{r_{b}}=i_{r_{c}}=0 \mathrm{~A}$. Since the observer is just on-line simulation of the linear induction motor LIM model, no observer gain is to be adjusted. The controlled linear induction motor LIM behavior with observed secondary currents was very close to behavior of controlled system feeding with the real secondary currents in numerical simulation. For the illustration of numerical results, a simulation of the linear induction motor drive controlled by zero average dynamic and fixed point inducting control ZAD-FPIC control strategies was made. The motor model used in simulation was the per phase equivalent circuit as shown in Figure 3.

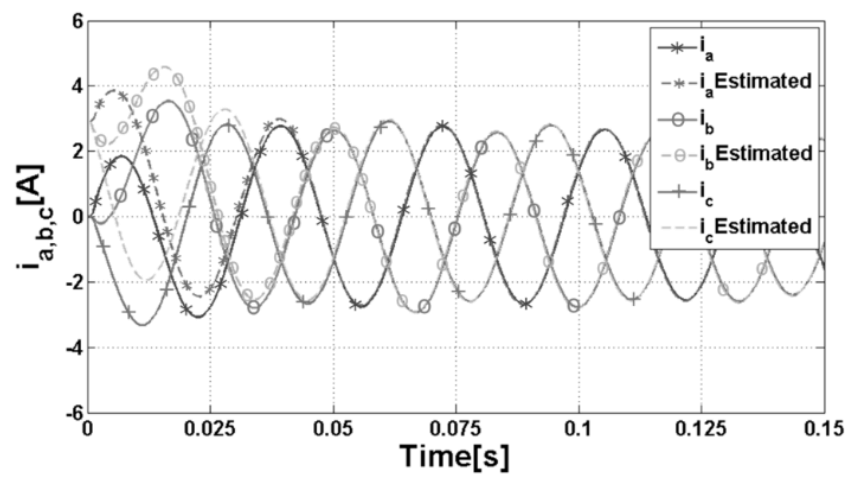

Figure 2. Response of the secondary current observer

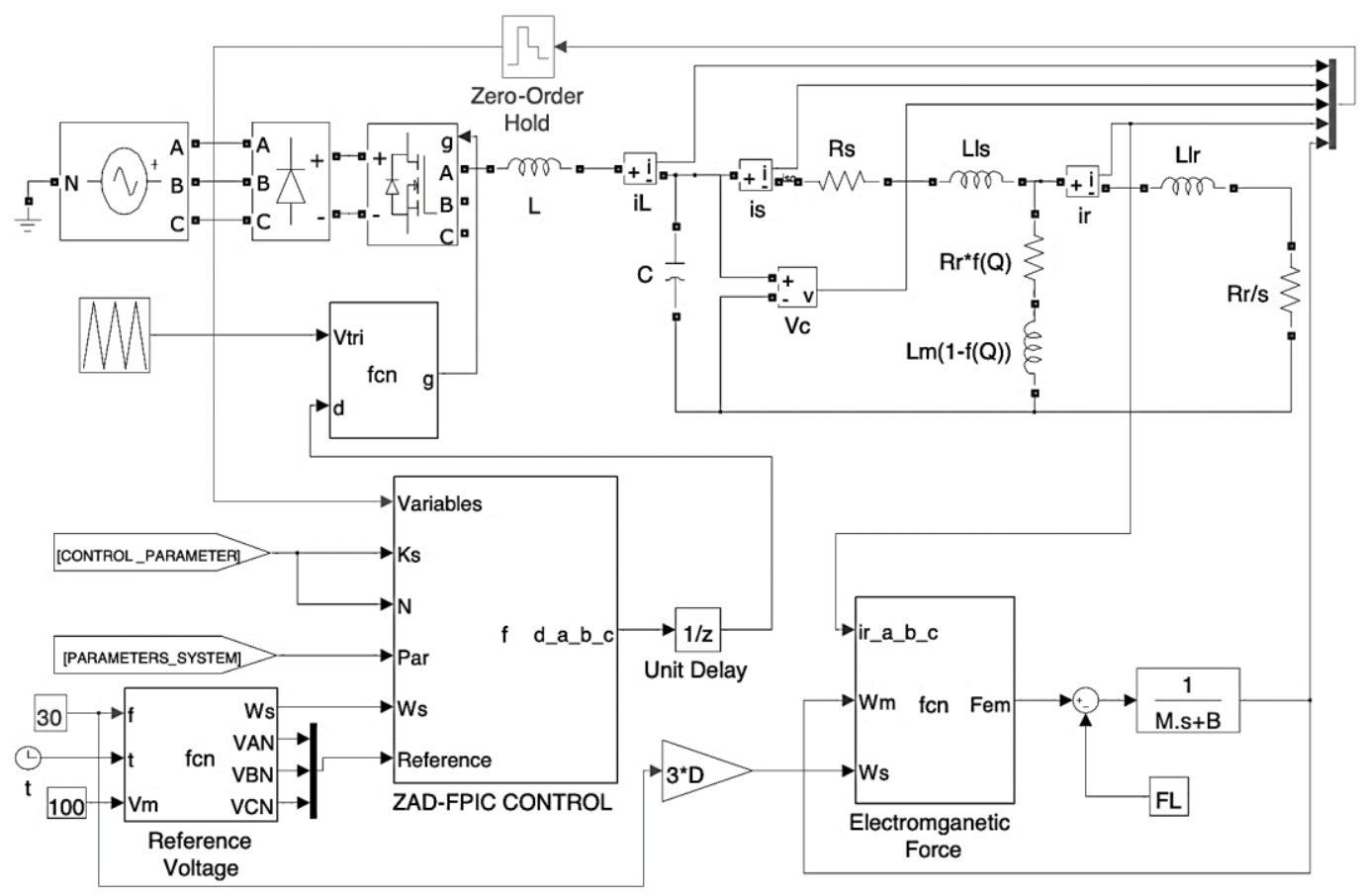

Figure 3. Equivalent circuit model per-phase for simulation

Figure 4 (a) shows the time behavior when the bifurcation parameter $K_{s}$ is 0.25 . The controlled voltage has chaotic behavior and has quite difference respect to the reference voltage for phase $a$. In Figure 4 (b) the tracking error of controlled voltage respect to the reference voltage is more low, in this case the $K_{s}$ value is 0.5 . Phase portrait for $i_{a}$ and $v_{a}$ variables shows a one-periodic solution for $K_{s}=0.5$. When $K_{s}=0.25$ the qualitative behavior is quite different as shown in Figure 5. 


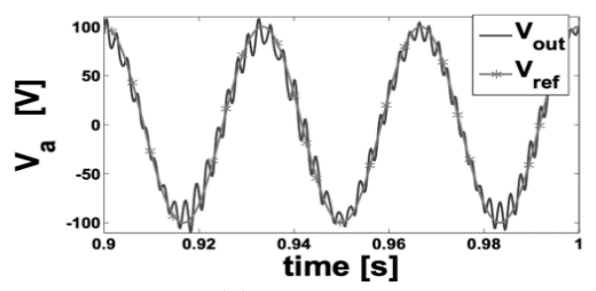

(a)

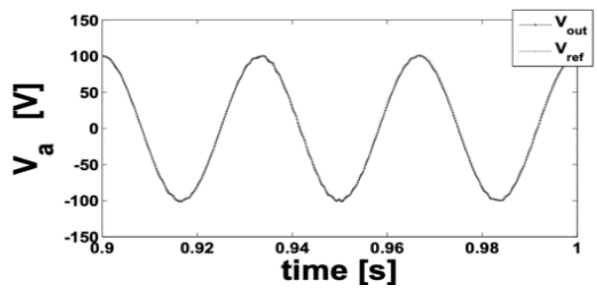

(b)

Figure 4. Time behavior for voltage motor (controlled voltage) of phase $a$ for (a) time behavior with $\mathrm{K}_{S}=0.25$ and (b) time behavior with $\mathrm{K}_{\mathrm{S}}=0.5$

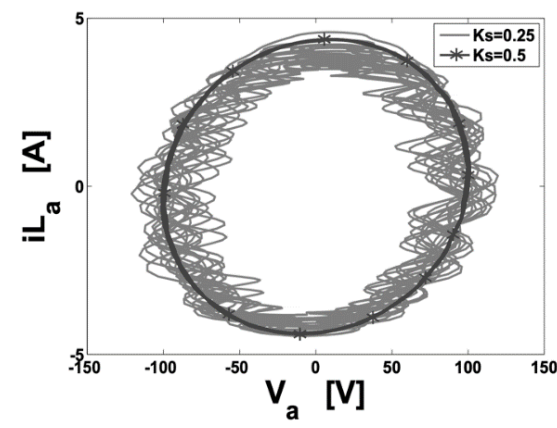

Figure 5. Phase portrait for $i_{a}$ and $v_{a}$ variables

Figure 6 (a) shows the time behavior when the bifurcation parameter $\mathrm{N}$ is 0.1 . The controlled voltage has chaotic behavior and has quite difference respect to the reference voltage for phase $a$. In Figure 6 (b) the tracking error of controlled voltage respect to the reference voltage is more low, in this case the $N$ value is 3.0. Phase portrait for $i_{a}$ and $v_{a}$ variables shows a one-periodic solution for $K_{s}=0.5$. When $K_{s}=0.25$ the qualitative behaviour is quite different as shown in Figure 7.

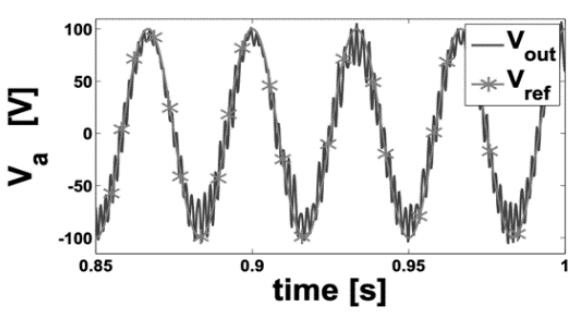

(a)

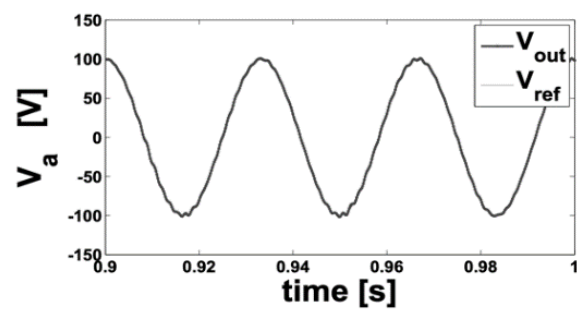

(b)

Figure 6. Time behavior for voltage motor (controlled voltage) of phase $a$ for (a) time behavior with $N=0.1$ and (b) time behavior with $N=3.0$

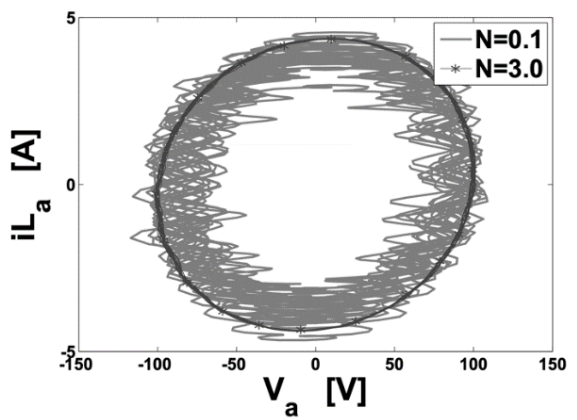

Figure 7. Phase portrait for $i_{a}$ and $v_{a}$ variables 


\section{CONCLUSION}

The control strategy zero average dynamic and fixed point inducting control ZAD-FPIC was designed and applied to three phasic converter with linear induction motor load. Because is not possible to measure the secondary currents, a secondary current observer was included in the system. For this system, simulations were performed. The stability of the closed loop system was analyzed using bifurcation diagrams, and stable and transitions to chaos were observed. Due to limitation in the mover path (1.5 meters), experiments with the control system were not made. Finally, were shown the bifurcation diagrams like a technique for to adjust controller parameters in ZAD and fixed point inducting control ZAD-FPIC controllers.

\section{ACKNOWLEDGEMENTS}

This work was supported by Universidad Católica de Manizales with the Grupo de Investigación en Desarrollos Tecnológicos y Ambientales and the Universidad Nacional de Colombia - Sede Manizales. This research received external funding from "Fondo Nacional de Financiamiento para la Ciencia, la Tecnología, y la Innovación, Fondo Francisco José de Caldas con contrato No 213-2018 con Código 58960.” Programa "Colombia Científica"

\section{REFERENCES}

[1] A. N. Abdullah and M. H. Ali, "Direct torque control of IM using PID controller," International Journal of Electrical and Computer Engineering, vol. 10, no. 1, pp. 617-625, 2020, doi: 10.11591/ijece.v10i1.pp617-625.

[2] A. J. Ali, L. A. Khalaf, and A. H. Ahmed, "Modeling and simulation of a 3-ф induction motor based on two types of WFA," International Journal of Electrical and Computer Engineering (IJECE), vol. 11, no. 2, pp. 110-1113, 2021, doi: 10.11591/ijece.v11i2.pp1105-1113.

[3] N. Toro, Y. A. Garcés, F. E. Hoyos, and E. N. Sanchez, "Parameter Estimation of Linear Induction Motor LabVolt 8228-02," in Proceedings of the Congreso Anual Asociación de Mexico de Control Automático, Saltillo, Mexican, pp. 1-6, 2011.

[4] N. Toro-Garcia, Y. A. Garcés-Gómez, and F. E. Hoyos, "Discrete and Continuous Model of Three-Phase Linear Induction Motors 'LIMs' Considering Attraction Force," Energies, vol. 12, no. 4, pp. 1-11, 2019, doi: 10.3390/en12040655.

[5] N. T. Garcia, Y. A. G. Gómez, and F. E. H. Velasco, "Parameter estimation of three-phase linear induction motor by a DSP-based electric-drives system," International Journal of Electrical \& Computer Engineering, vol. 10, no. 1, pp. 626-636, 2020, doi: 10.11591/ijece.v10i1.pp626-636.

[6] N. T. Garcia, Y. A. G. Gómez, and F. E. H. Velasco, "Discrete and continuous model of three-phase linear induction motors considering attraction force and end-effects," International Journal of Power Electronics and Drive Systems, vol. 11, no. 4, pp. 1737-1749, 2020, doi: 10.11591/ijpeds.v11.i4.pp1737-1749.

[7] N. T. García, "Dynamical analysis of three phase systems controlled by ZAD-FPIC Techniques," Universidad National de Colombia, p. 205, 2012.

[8] E. Fossas and R. Grino, "Quasi-sliding control based on pulse width modulation, zero averaged dynamics and the L2 norm," Advances in Variable Structure Systems. Analysis. Integration and Applications (6th International Workshop on Variable Structure Systems (VSS'2000), pp. 335-344, 2000.

[9] F. Angulo, G. Olivar, and A. Taborda, "Continuation of periodic orbits in a ZAD-strategy controlled buck converter," Chaos, Solitons \& Fractals, vol. 38, no. 2, pp. 348-363, 2008, doi: 10.1016/j.chaos.2007.04.023.

[10] F. Angulo, E. Fossas, and G. Olivar, "Transition from periodicity to chaos in a PWM-controlled buck converter with ZAD strategy," International Journal of Bifurcation and Chaos, vol. 15, no. 10, pp. 3245-3264, 2005, doi: $10.1142 / \mathrm{S} 0218127405014015$.

[11] F. Angulo García, Análisis de la dinámica de convertidores electrónicos de potencia usando PWM basado en promediado cero de la dinámica del error (ZAD). Catalunya, 2004.

[12] J. Taborda, "Análisis de bifurcaciones en sistemas de segundo orden usando pwm y promediado cero de la dinámica del error," Universidad Nacional de Colombia - Sede Manizales, 2006.

[13] F. Angulo, E. Fossas, C. Ocampo, and G. Olivar, "Stabilization of chaos with fpic: Application to zad-strategy buck converters," IFAC Proceedings Volumes, vol. 38, no. 1, pp. 1183-1188, 2005, doi: 10.3182/20050703-6-CZ-1902.00854.

[14] F. Angulo, J. E. Burgos, and G. Olivar, "Chaos stabilization with TDAS and FPIC in a buck converter controlled by lateral PWM and ZAD," Mediterranean Conference on Control \& Automation, 2007, pp. 1-6, doi: 10.1109/MED.2007.4433846.

[15] F. Angulo, G. Olivar, J. Taborda, and F. Hoyos, "Nonsmooth dynamics and fpic chaos control in a dc-dc zad-strategy power converter," Sixth Euromech Nonlinear Dynamics Conference, 2008, vol. 55, pp. 2392-2401.

[16] A. J. Morelo, S. C. Trujillo, and F. E. Hoyos, "Simulation, bifurcation, and stability analysis of a SEPIC converter controlled with ZAD.," International Journal of Electrical \& Computer Engineering, vol. 10, no. 1, pp. 728-737, 2020, doi: 10.11591/ijece.v10i1.pp728-737.

[17] F. E. Hoyos, J. E. Candelo, and J. A. Taborda, "Selection and validation of mathematical models of power converters using rapid modeling and control prototyping methods," International Journal Electrical and Computer Engineering, vol. 8, no. 3, pp. 15511568, 2018, doi: 10.11591/ijece.v8i3.pp1551-1568.

[18] S. Banerjee and G. Verghese, "Nonlinear phenomena in power electronics," IEEE Press. Piscataway, 2001.

[19] A. Suzdalenko, J. Zakis, P. Suskis, and L. Ribickis, "Bidirectional single-loop current sensorless control applied to NPC multilevel converter considering conduction losses," International Journal of Power Electronics and Drive Systems, vol. 11, no. 4, pp. 1945-1957, 2020, doi: 10.11591/ijpeds.v11.i4.pp1945-1957.

[20] P. Mishra, A. Kumar Pradhan, and P. Bajpai, "Voltage control of PV inverter connected to unbalanced distribution system," Renew. Power Gener. IET, vol. 13, no. 9, pp. 1587-1594, 2019, doi: 10.1049/iet-rpg.2018.6219.

[21] N. Mohan, T. Undeland, and W. Robbins, Power electronics: converters. Aplications and design, 3rd ed. J. Wiley, 2003.

[22] N. Mohan, First course on power electronics and drives. Mnpere: J. Wiley, 2003.

[23] P. Mishra, A. Banerjee, M. Ghosh, and C. B. Baladhandautham, "Digital pulse width modulation sampling effect embodied 
steady-state time-domain modeling of a boost converter driven permanent magnet DC brushed motor," International Transactions on Electrical Energy Systems, vol. 31, no. 8, pp. 1-18, 2021, doi: 10.1002/2050-7038.12970.

[24] R. Q. Machado, S. Buso, and J. A. Pomilio, “A line-interactive single-phase to three-phase converter system,” IEEE Transactions on Power Electronics, vol. 21, no. 6, pp. 1628-1636, 2006, doi: 10.1109/TPEL.2006.882963.

[25] H. Hu, V. Yousefzadeh, and D. Maksimović, "Nonuniform A/D quantization for improved dynamic responses of digitally controlled DC-DC converters," IEEE Transactions on Power Electronics, vol. 23, no. 4, pp. 1998-2005, 2008, doi: 10.1109/TPEL.2008.924845.

[26] J. A. Taborda, F. Angulo, and G. Olivar, "Estimation of parameters in Buck converter with Digital-PWM control based on ZAD strategy," 2011 IEEE Second Latin American Symposium on Circuits and Systems (LASCAS), 2011, pp. 1-4, doi: 10.1109/LASCAS.2011.5750302.

[27] C. W. Fung, C. P. Liu, and M. H. Pong, "A diagrammatic approach to search for minimum sampling frequency and quantization resolution for digital control of power converters," 2007 IEEE Power Electronics Specialists Conference, 2007, pp. 826-832, doi: 10.1109/PESC.2007.4342095.

\section{BIOGRAPHIES OF AUTHORS}
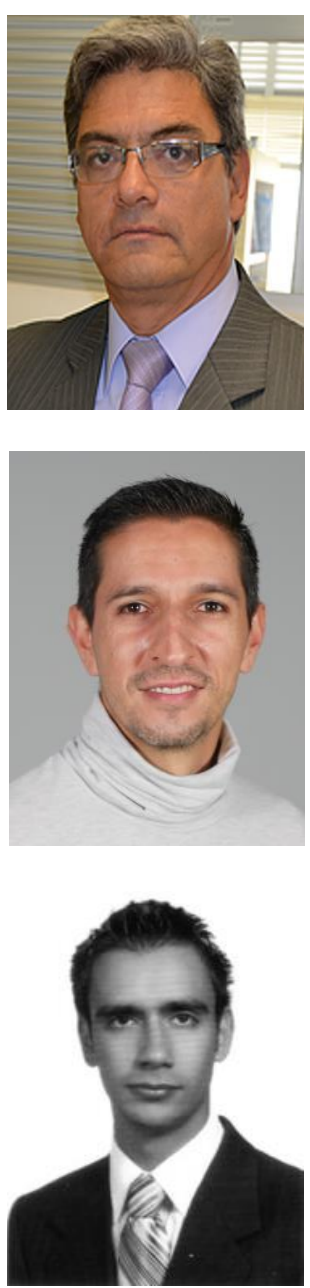

Nicolás Toro García (iD) SC P received a B.S. in electrical engineering and Ph.D. in automatics from Universidad Nacional de Colombia, Manizales in 1983 and 2012, respectively, as well as an M.S. in production automatic systems from Universidad Tecnológica de Pereira, Colombia in 2000. He is currently an Associate Professor in the Department of Electrical Engineering, Electronics, and Computer Science, Universidad Nacional de Colombia, Sede de Manizales. His research interests include nonlinear control, nonlinear dynamics of nonsmooth systems, and power electronic converters. He is a member of the reasearch group in power resources GIRE (Código colombiano de registro: COL0144229), at Universidad Nacional de Colombia. He can be contacted at email: ntoroga@unal.edu.co.

Yeison Alberto Garcés-Gómez (iD SA Sc P Received bachelor's degree in Electronic Engineering, and master's degrees and $\mathrm{PhD}$ in Engineering from Electrical, Electronic and Computer Engineering Department, Universidad Nacional de Colombia, Manizales, Colombia, in 2009, 2011 and 2015, respectively. He is Full Professor at the Academic Unit for Training in Natural Sciences and Mathematics, Universidad Católica de Manizales, and teaches several courses such as Experimental Design, Statistics, and Physics. His main research focus is on applied technologies, embedded system, power electronics, power quality, but also many other areas of electronics, signal processing and didactics. He published more than 30 scientific and research publications, among them more than 10 journal papers. He worked as principal researcher on commercial projects and projects by the Ministry of Science, Tech and Innovation, Republic of Colombia. He can be contacted at email: ygarces@ucm.edu.co.

Vladimir Henao Céspedes (iD) $8 \mathrm{SC}$ P received the B.S degree in electronic engineering, the M.Sc. degree and the PhD. On engineering from Universidad Nacional de Colombia, Manizales. $\mathrm{He}$ currently an Associate Professor in the Faculty of Engineering and Architecture, telecommunications engineering, at the Universidad Católica de Manizales, Manizales. His research interests include electromagnetic compatibility, electromagnetic pollution, and lightning discharges. He is member of the Research Group on Tecnhonological and Environmental Development GIDTA. He can be contacted at email: vhenao@ucm.edu.co. 